\title{
DPD is a molecular determinant of capecitabine efficacy in colorectal cancer
}

\author{
DANIEL VALLBÖHMER ${ }^{1,2}$, DONG YUN YANG ${ }^{1}$, HIDEKAZU KURAMOCHI ${ }^{1}$, D. SHIMIZU ${ }^{1}$, \\ KATHLEEN D. DANENBERG ${ }^{3}$, JAN LINDEBJERG ${ }^{4}$, JENS NEDERBY NIELSEN $^{4}$, \\ ANDERS JAKOBSEN $^{4}$ and PETER V. DANENBERG ${ }^{1}$
}

\author{
${ }^{1}$ Norris Comprehensive Cancer Center, University of Southern California, 1441 East Lake Avenue, Los Angeles, \\ CA 90033, USA; ${ }^{2}$ Department of Visceral and Vascular Surgery, University of Cologne, Kerpenerstr. 62 \\ D-50937 Cologne, Germany; ${ }^{3}$ Response Genetics, Inc., 1640 Marengo Street, Los Angeles, CA 90033, USA; \\ ${ }^{4}$ Danish Colorectal Cancer Group South, Department of Oncology, University \\ of Southern Denmark,Vejle Hospital, Kabbeltoft 25, 7100 Vejle, Denmark
}

Received August 23, 2006; Accepted November 1, 2006

\begin{abstract}
Capecitabine is a fluoropyrimidine-based drug that offers physicians a more convenient treatment for advanced colorectal cancer (CRC), with manageable toxicity and antitumor activity comparable to that of continuous-infusion therapies with 5-fluorouracil (5-FU). However, there are no validated and established predictive factors for clinical outcome of capecitabine efficacy in CRC. The gene expressions of the pyrimidine metabolism enzymes dihydropyrimidine dehydrogenase (DPD), thymidine phosphorylase (TP) and thymidylate synthase (TS) have previously been shown to be response determinants of fluoropyrimidine-based drugs in various tumors. Therefore, we investigated whether intratumoral mRNA expression levels of these genes are also associated with the clinical outcome of patients with metastatic CRC treated with first-line capecitabine. Thirty-seven patients with metastatic CRC were enrolled in this study and treated with single agent capecitabine. The intratumoral mRNA levels of DPD, TP and TS were assessed from paraffinembedded tissue samples using laser-capture-microdissection methods and quantitative real-time PCR. There were 20 women and 17 men with a median age of 61 years (range 49-74). The median progression-free survival was 6.7 months (95\% CI, 4.8-11.6 months), with a median follow-up of 14.4 months (range 1.3-18.7 months). Complete response was observed in $1(3 \%)$, partial response in $6(20 \%)$, stable disease in $14(47 \%)$ and progressive disease in $9(30 \%)$ patients (response was inevaluable in 7 patients). Higher
\end{abstract}

Correspondence to: Dr Peter V. Danenberg, University of Southern California/Norris Comprehensive Cancer Center, NOR 5318, 1441 East Lake Avenue, Los Angeles, CA 90033, USA

E-mail: pdanenbe@usc.edu

Key words: colorectal cancer, capecitabine, molecular determinants gene expression levels of DPD were associated with resistance to capecitabine ( $\mathrm{P}=0.032$; Kruskal-Wallis test). Patients with a lower mRNA amount of DPD $(\leq 0.46)$ had a longer progression-free survival compared with patients that had a higher mRNA amount ( 8.0 vs. 3.3 months; adjusted $\mathrm{P}=0.048$; log-rank test).

This pilot study suggests that intratumoral gene expression levels of DPD may be useful in predicting the clinical outcome of patients with metastatic CRC with first-line single agent capecitabine treatment. Our data should be validated in larger and prospective clinical trials.

\section{Introduction}

In the 1950s 5-fluorouracil (5-FU) was first synthesized by Heidelberger et al (1). Fifty years later, 5-FU still remains an important component of many standard treatments in the multimodal therapy of colorectal cancer (CRC) (2). It is well established that continuous-infusion 5-FU administration, in combination with leucovorin, is more effective and associated with a better toxicity profile than intravenous bolus application (3). However, intravenous 5-FU administration is costly, inconvenient for patients and potentially associated with morbidity, including hematological toxicity and gastrointestinal toxicity (2). To overcome these disadvantages but still provide the benefits of continuous-infusion dosing, oral fluoropyrimidines were developed.

Capecitabine $\left(\mathrm{Xeloda}^{\circledR}\right)$ is a prodrug that undergoes a three-step enzymatic conversion to 5-FU (4). This oral fluoropyrimidine was already shown to offer a more convenient treatment for advanced CRC, with manageable toxicity and antitumor activity comparable to that of continuous-infusion therapies with 5-FU. In fact, two randomized clinical studies comparing capecitabine to the parenteral treatment with 5-FU and leucovorin demonstrated that the rate of objective response in patients treated with capecitabine was moderately improved $(5,6)$. In addition, capecitabine demonstrated clinically meaningful safety advantages and the convenience of an oral agent. 
Although capecitabine has clinical activity in patients with colorectal cancer, primary and acquired treatment resistance is common. Therefore, the potential to identify those individuals most likely to benefit from a given treatment assumes increasing importance. In previous studies, the expression levels of dihydropyrimidine dehydrogenase (DPD), thymidine phosphorylase (TP) and thymidylate synthase (TS) have been implicated as molecular response determinants for 5-FU based chemotherapies not only in metastatic CRC but other cancers as well (7-13). However, the role of these factors as response determinants for capecitabine has not been fully studied. TS, a rate limiting enzyme of DNA synthesis, is the major target for the anti-tumor activity of fluoropyrimidines and thus historically has been considered as the main candidate respone determinant of tumors to 5-FU-based therapy. Recently, some of the present authors (J.L., J.N.N. and A.J.) performed a study showing a significant correlation between the predominant immunohistochemical reaction pattern of TS and response (but not between immunohistochemical score and response) to capecitabine in the same CRC patients as in this study (14). TP is thought to be part of an activation pathway that converts the pyrimidine base 5-FU to the nucleotide form FdUMP, which is the actual TS inhibitor. Preclinical studies have shown that overexpression of TP, catalyzing the final step in conversion of capecitabine to 5-FU, is associated with increased sensitivity to capecitabine or doxifluridine, due to greater conversion to 5-FU (15-17). Meropol et al (J Clin Oncol, ASCO 22: abs. 3520, 2004) have reported that higher TP levels are associated with response to a capecitabinebased regimen although the protocol included irinotecan as well. DPD is a catabolic enzyme that degrades 5-FU and thus its activity should theoretically bear an inverse relationship to 5-FU efficacy. This prediction has been confirmed repeatedly in the case of 5-FU-based chemotherapies, but at this time, we know of no reports concerning the relationship between DPD expression and tumor response to capecitabine $(8,9,13)$.

The availability of FFPE tissue specimens of tumors from a group of CRC patients who were treated with capecitabine as a first-line single agent provided the opportunity to obtain an unambiguous evaluation of DPD, TP and TS gene expressions as response determinants to this drug without the potentially obscuring effects of other co-administered agents. In this study, we used laser capture microdissection to isolate tumor areas in FFPE tissue samples and then measured relative mRNA levels of DPD, TP and TS by quantitative RT-PCR to determine if the expressions of these genes are associated with the clinical outcome of patients with metastatic CRC treated with first-line capecitabine.

\section{Materials and methods}

Patients. The study included 37 patients with confirmed metastatic CRC with at least one measurable lesion. Biopsies from the primary tumor were obtained at operation. The study was performed according to the Helsinki II Declaration and approved by the regional ethics committee.

All 37 patients received first-line capecitabine based chemotherapy. They received capecitabine $1250 \mathrm{mg} / \mathrm{m}^{2}$ twice daily as part of a phase II trial. The treatment was given for a period of 14 days followed by a 7-day rest period. The clinical evaluation and response criteria of all patients in the study are listed below.

Clinical evaluation and response criteria. CT imaging for response was performed every 6 weeks. In general, responders to therapy were classified as those patients whose tumor burden had decreased by $50 \%$ or more for at least 6 weeks. Patients with evaluable but non-measurable disease, whose tumor and all evidence of disease had disappeared, were classified as showing complete response (CR). Responders with anything less than complete response were simply categorized as demonstrating partial response (PR). Nonresponders were, likewise, divided into two separate classification groups. The first of these, progressive disease (PD), was defined as a $25 \%$ or more increase in tumor burden (compared to the smallest measurement) or the appearance of new lesions. Further, non-responsive patients, who did not progress within the first 12 weeks following the start of capecitabine, were classified as having stable disease (SD).

Microdissection. Paraffin-embedded tumor blocks were reviewed for quality and tumor content by a pathologist. Tenmicrometer-thick sections were obtained from the identified areas with the highest tumor concentration. Sections were mounted on uncoated glass slides. For histology diagnosis, three representative sections, consisting of the beginning, the middle and the end of sections of the tissue were stained with $\mathrm{H} \& \mathrm{E}$ by the standard method. Before microdissection, sections were deparaffinized in xylene for $10 \mathrm{~min}$ and hydrated with $100 \%, 95 \%$ and finally $70 \%$ ethanol. The sections were washed in $\mathrm{H}_{2} \mathrm{O}$ for $30 \mathrm{sec}$ and then stained with nuclear fast red (NFR, American MasterTech Scientific, Inc., Lodi, CA) for $20 \mathrm{sec}$ and rinsed in $\mathrm{H}_{2} \mathrm{O}$ for $30 \mathrm{sec}$. Samples were then dehydrated with $70 \%, 95 \%$ and $100 \%$ ethanol for $30 \mathrm{sec}$ each, followed by xylene for $10 \mathrm{~min}$. The slides were completely air-dried. If the histology of the sample was homogeneous and contained $>90 \%$ tissue of interest, the specimen was dissected from the slides using a scalpel. All other sections of interest were selectively isolated by laser capture microdissection (P.A.L.M. Microsystem, Leica, Wetzlar, Germany) according to the standard procedure (18). The dissected particles of tissue were transferred to a reaction tube containing $400 \mu 1$ of RNA lysis buffer.

RNA isolation and cDNA synthesis. The tissue samples to be extracted were placed in a $0.5 \mathrm{ml}$, thin walled tube containing $400 \mu \mathrm{l}$ of $4 \mathrm{M}$ dithiothreitol (DTT)-GITC/sarc (4 M guanidinium isothiocyanate, $50 \mathrm{mM}$ Tris- $\mathrm{HCl}, \mathrm{pH} 7.5$, 25 mM EDTA) (Invitrogen; \#15577-018). The samples were heated at $92^{\circ} \mathrm{C}$ for $30 \mathrm{~min}$ and then transferred to a $2 \mathrm{ml}$ centrifuge tube. To the tissue suspensions were added $50 \mu 1$ of $2 \mathrm{M}$ sodium acetate, $\mathrm{pH} 4.0$, followed by $600 \mu \mathrm{l}$ of freshly prepared phenol/chloroform/isoamyl alcohol (250:50:1). The tubes were vortexed for $15 \mathrm{sec}$, placed on ice for $15 \mathrm{~min}$ and then centrifuged at $13,000 \mathrm{rpm}$ for $8 \mathrm{~min}$ in a chilled $\left(8^{\circ} \mathrm{C}\right)$ centrifuge. The upper aqueous phase (250-350 $\mu 1)$ was carefully removed and placed in a $1.5 \mathrm{ml}$ centrifuge tube. Glycogen (10 $\mu 1)$ and 300-400 $\mu 1$ of isopropanol were added and the 
Table I. Primers and probes.

\begin{tabular}{|c|c|c|c|c|}
\hline Gene & $\begin{array}{l}\text { GenBank } \\
\text { Accession }\end{array}$ & Forward primer $\left(5^{\prime}-3^{\prime}\right)$ & Reverse primer $\left(5^{\prime}-3^{\prime}\right)$ & Taqman probe $\left(5^{\prime}-3^{\prime}\right)$ \\
\hline ß-actin & NM_001101 & GAGCGCGGCTACAGCTT & TCCTTAATGTCACGCACGATTT & ACCACCACGGCCGAGCGG \\
\hline DPD & NM_000110 & AGGACGCAAGGAGGGTTTG & GTCCGCCGAGTCCTTACTGA & CAGTGCCTACAGTCTCGAGTCTGCCAGTG \\
\hline $\mathrm{TP}$ & NM_001953 & CCTGCGGACGGAATCCT & GCTGTGATGAGTGGCAGGCT & CAGCCAGAGATGTGACAGCCACCGT \\
\hline TS & NM_001071 & GCCTCGGTGTGCCTTTCA & CCCGTGATGTGCGCAAT & TCGCCAGCTACGCCCTGCTCA \\
\hline
\end{tabular}

DPD, dihydropyrimidine dehydrogenase; TP, thymidine phosphorylase; TS, thymidylate synthase.

Table II. Demographic and clinical parameters of patients with advanced CRC treated with first-line capecitabine.

\begin{tabular}{lcr}
\hline Characteristics & Frequency & $\%$ \\
\hline Median age, years (range) & $61(49-74)$ & \\
Gender & & \\
$\quad$ Female & 20 & 44 \\
$\quad$ Male & 17 & \\
Response & & 3 \\
$\quad$ Complete response & 1 & 20 \\
$\quad$ Partial response & 6 & 37 \\
$\quad$ Stable disease & 14 & \\
$\quad$ Progressive disease & 9 & \\
$\quad$ Inevaluable/early off study & 7 & \\
\hline
\end{tabular}

samples vortexed for $10-15 \mathrm{sec}$. The tubes were placed at $-20^{\circ} \mathrm{C}$ for 30-45 min to precipitate the RNA. The samples were then centrifuged at $13,000 \mathrm{rpm}$ for $7 \mathrm{~min}$ in a chilled $\left(8^{\circ} \mathrm{C}\right)$ centrifuge. The supernatant was poured off and $500 \mu 1$ of $75 \%$ ethanol was added. The tubes were centrifuged at 13,000 rpm for $6 \mathrm{~min}$ in a chilled $\left(8^{\circ} \mathrm{C}\right)$ centrifuge. The supernatant was carefully poured off so as not to disturb the RNA pellet and the samples were quick-spun for $15 \mathrm{sec}$ at $13,000 \mathrm{rpm}$. The remaining ethanol was removed with a $20 \mu 1$ pipette and the samples air-dried for $15 \mathrm{~min}$. The pellet was re-suspended in $50 \mu 1$ of $5 \mathrm{mM}$ Tris (this is a proprietary procedure of Response Genetics, Inc., Los Angeles, CA; United States patent number $6,248,535)$. cDNA was prepared as previously described (19).

Real-time PCR quantification of mRNA expression. Quantitation of DPD, TP and TS and an internal reference gene (ß-actin) was done using a fluorescence based real-time detection method [ABI PRISM 7900 Sequence detection System (TaqMan ${ }^{\circledR}$ ) Perkin-Elmer (PE) Applied Biosystem, Foster City, CA, USA]. The PCR reaction mixture consisted $1200 \mathrm{nM}$ of each primer, $200 \mathrm{nM}$ probe, $0.4 \mathrm{U}$ of AmpliTaq Gold Polymerase, $200 \mathrm{nM}$ each dATP, dCTP, dGTP, dTTP, $3.5 \mathrm{mM} \mathrm{MgCl}_{2}$ and $1 \mathrm{X}$ Taqman buffer A containing a reference dye, to a final volume of $20 \mu \mathrm{l}$ (all reagents from PE Applied Biosystems). Cycling conditions were $50^{\circ} \mathrm{C}$ for $2 \mathrm{~min}$, $95^{\circ} \mathrm{C}$ for $10 \mathrm{~min}$, followed by 46 cycles at $95^{\circ} \mathrm{C}$ for $15 \mathrm{sec}$ and $60^{\circ} \mathrm{C}$ for $1 \mathrm{~min}$. The primers and probes used are listed in Table I.

Gene expression values (relative mRNA levels) are expressed as ratios (differences between the $\mathrm{Ct}$ values) between the gene of interest and an internal reference gene (B-actin) that provides a normalization factor for the amount of RNA isolated from a specimen. In validating our assays, we found that gene expression values were reproducible and reliable if $\mathrm{Ct}$ values were below a certain maximum. This number varied somewhat for each gene but in general, we considered $\mathrm{Ct}$ values below 37 to be sufficiently reliable for gene expression measurements. Those gene expressions with $\mathrm{Ct}$ 's above 37 were not reported.

Statistical analysis. Tumor response to capecitabine and progression-free survival were our primary endpoints in this study. The progression-free survival time was calculated as the period from the first day of capecitabine until the first observation of disease progression or death from any cause. If a patient had not progressed or died, progression-free survival was censored at the time of the last follow-up.

Gene expression values are expressed as ratios between two absolute measurements, that of the gene of interest and that of the internal reference gene, $\beta$-actin. The associations between gene expression levels and response to capecitabine (complete response, partial response, stable disease, and progressive disease) were evaluated by the Kruskal-Wallis test. To evaluate the associations between the expression level of each gene and progression-free survival, the expression level was categorized into a low and a high value at optimal cutpoints. The maximal $\chi^{2}$ method of Miller and Siegmund (20) and Halpern (21) was used to determine which gene expression (optimal cutpoint) best segregated patients into poor- and good-prognosis subgroups (in terms of likelihood of pro-gression-free survival).

All reported P-values were two-sided. The analyses were performed using the SAS statistical package version 9.0 (SAS Institute Inc., Cary, NC).

\section{Results}

There were 20 female and 17 male patients with a median age of 61 (range 49-74) in our subject population. All patients were assessable for associating gene expression levels of DPD, TP and TS with response and progressionfree survival. The median progression-free survival was 6.7 
Table III. Gene expression levels relative to the internal reference gene $\beta$-actin of the analyzed genes.

\begin{tabular}{lcc}
\hline Gene & $\begin{array}{c}\text { No. } \\
\text { of Patients }\end{array}$ & $\begin{array}{c}\text { mRNA expression levels relative } \\
\text { to } ß \text {-actin } \times 10^{-3} \\
\text { Median (range) }\end{array}$ \\
\hline DPD & 37 & $0.22(0.01-0.96)$ \\
TP & 37 & $1.58(0.55-7.22)$ \\
TS & 37 & $1.36(0.31-6.09)$
\end{tabular}

DPD, dihydropyrimidine dehydrogenase; TP, thymidine phosphorylase; TS, thymidylate synthase.

months (95\% CI, 4.8-11.6 months), with a median follow-up of 14.4 months (range 1.3-18.7 months). Complete response was observed in $1(3 \%)$, partial response in $6(20 \%)$, stable disease in $14(47 \%)$ and progressive disease in $9(30 \%)$ patients (response was inevaluable in 7 patients) (Table II).

Gene expression levels of DPD, TP and TS. Gene expression of DPD, TP and TS was measurable in all 37 samples (100\%). The median gene expression levels, relative to the internal reference gene ( $ß$-actin), of the analyzed genes are listed in Table III.

Gene expression levels and response of patients receiving first-line capecitabine-based chemotherapy. The only factor that showed a significant correlation between response and gene expression levels was DPD (Table IV and Fig. 1). The patient with a complete reponse had a median gene expression level of $0.01 \times 10^{-3}$, patients with a partial response $0.06 \times 10^{-3}$, patients with stable disease $0.29 \times 10^{-3}$ and patients with progressive disease $0.2 \times 10^{-3}(\mathrm{P}=0.032$, Kruskal-Wallis test).

Gene expression levels and progression-free survival in patients receiving first-line capecitabine-based chemotherapy. Gene expression cut-off values that best segregated patients into poor- and good prognosis subgroups (in terms of likelihood of progression-free survival) were defined using the maximal $\chi^{2}$ method of Miller and Siegmund (20) and Halpern (21). The log-rank test was used to evaluate the

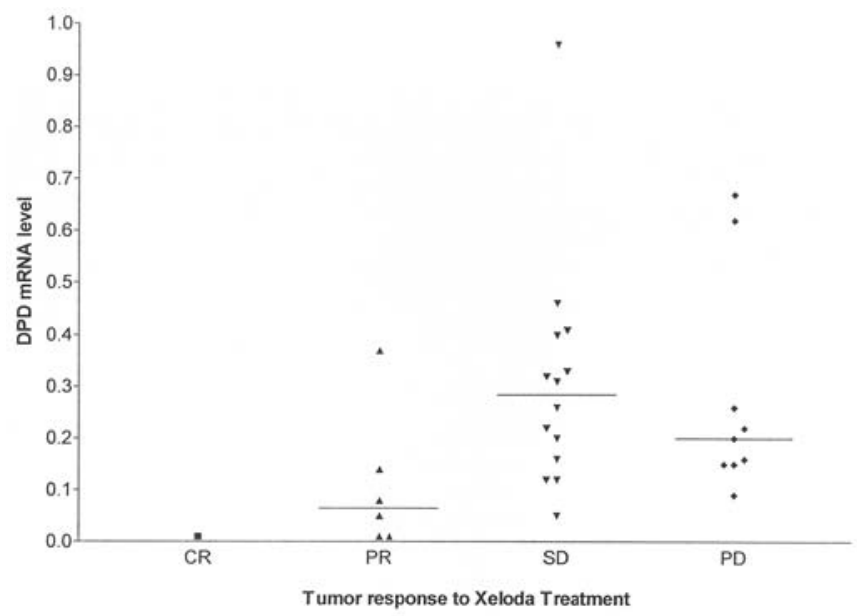

Figure 1. Dihydropyrimidine dehydrogenase mRNA levels by tumor response to capecitabine treatment in patients with advanced colorectal cancer. DPD, dihydropyrimidine dehydrogenase.

association between gene expression levels and survival for each single gene. The best cut-off value for DPD gene expression was found to be $0.47 \times 10^{3}$, with $31 \mathrm{DPD}$ expression levels below this value ('low' expression) and 6 above the cut-off value ('high' expression). The median survival of patients with low DPD mRNA levels was 8.0 months (95\% CI, 5.3-12.9 months) and 3.3 months (95\% CI, 1.9-4.8 months) in patients with high DPD mRNA levels $(\mathrm{P}=0.048$; log-rank test) (Table $\mathrm{V}$ and Fig. 2A). The association between expression levels of the other genes and progression-free survival did not show significant results or relevant trends, as shown in Table $\mathrm{V}$ and Fig. 2B and $\mathrm{C}$.

\section{Discussion}

In this report, we present data on the relationship between clinical outcomes in 37 patients with metastatic CRC receiving first-line capecitabine chemotherapy and mRNA expression of TS, TP and DPD, which have often been previously implicated in the anti-tumor activity of 5-FU based therapies (7-13). Among these 3 molecular factors, we found that only intratumoral mRNA expression levels of DPD were significantly associated with response to capecitabine treatment. Also, we showed that patients with a lower mRNA

Table IV. mRNA expression level of genes and tumor response to capecitabine therapy in patients with advanced colorectal cancer.

\begin{tabular}{|c|c|c|c|c|c|c|c|c|c|c|c|c|}
\hline \multirow[b]{2}{*}{ Gene } & \multicolumn{2}{|c|}{$\mathrm{CR}$} & \multicolumn{3}{|c|}{ Partial response } & \multicolumn{3}{|c|}{ Stable disease } & \multicolumn{3}{|c|}{ Progressive disease } & \multirow[b]{2}{*}{$\mathrm{P}$ value $^{\mathrm{a}}$} \\
\hline & $\mathrm{N}$ & Median & $\mathrm{N}$ & Median & (Min-Max) & $\mathrm{N}$ & Median & (Min-Max) & $\mathrm{N}$ & Median & (Min-Max) & \\
\hline DPD & 1 & 0.01 & 6 & 0.06 & $(0.01-0.37)$ & 14 & 0.29 & $(0.05-0.96)$ & 9 & 0.20 & $(0.09-0.67)$ & 0.032 \\
\hline $\mathrm{TP}$ & 1 & 3.04 & 6 & 1.48 & $(0.64-2.00)$ & 14 & 1.58 & $(0.55-7.22)$ & 9 & 1.58 & $(0.92-2.60)$ & 0.47 \\
\hline $\mathrm{TS}$ & 1 & 0.97 & 6 & 0.86 & $(0.52-2.04)$ & 14 & 1.66 & $(0.63-6.09)$ & 9 & 1.36 & $(0.31-4.53)$ & 0.49 \\
\hline
\end{tabular}

${ }^{a}$ The Kruskal-Wallis test. DPD, dihydropyrimidine dehydrogenase; TP, thymidine phosphorylase; TS, thymidylate synthase. 
Table V. mRNA expression level of genes and time to progression in patients with advanced colorectal cancer receiving capecitabine therapy.

\begin{tabular}{|c|c|c|c|c|}
\hline Gene & $\mathrm{N}$ & $\mathrm{RR}$ & $(95 \% \mathrm{CI})$ & P-value \\
\hline \multicolumn{5}{|l|}{ DPD } \\
\hline$\leq 0.46$ & 31 & 1 & Reference & \\
\hline$>0.46$ & 6 & 3.64 & $(1.15-11.52)$ & 0.048 \\
\hline \multicolumn{5}{|l|}{$\mathrm{TP}$} \\
\hline$\leq 1.20$ & 7 & 1 & Reference & \\
\hline$>1.20$ & 30 & 2.84 & $(0.85-9.53)$ & 0.38 \\
\hline \multicolumn{5}{|l|}{ TS } \\
\hline$\leq 2.35$ & 32 & 1 & Reference & \\
\hline$>2.35$ & 5 & 3.06 & $(1.09-8.60)$ & 0.13 \\
\hline
\end{tabular}

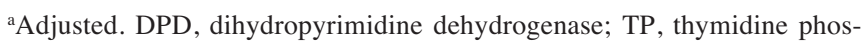
phorylase; TS, thymidylate synthase.

amount of DPD had a longer progression-free survival compared with patients that had a higher mRNA amount.

DPD represents a key enzyme of 5-FU metabolism. This rate-limiting enzyme of 5-FU catabolism inactivates $>80 \%$ of the drug in the liver (22). It has been suggested that low levels of DPD may increase bioavailability of the drug, thereby improving response. Clinical studies have already shown in patients with metastatic CRC receiving intravenous 5-FU based chemotherapy that low intratumoral DPD expression is significantly associated with a better response to 5 -FU $(13,23)$. Thus, since capecitabine is a pro-drug of $5-\mathrm{FU}$, it is reasonable to expect that low DPD expression would similarly be associated with response and prognosis of metastatic CRC patients treated with this drug. Recent studies by Tsuji et al (24) and Ichikawa et al (9) found a correlation between intratumoral DPD expression in patients with colorectal cancer and response to another 5-FU prodrug, the oral fluoropyrimidine uracil/tegafur (UFT). Both of their studies, which included patients with stage II/III as well as metastatic colorectal cancer, demonstrated that high gene expression levels of DPD were associated with resistance to the treatment with the oral fluoropyrimidines. These data and our findings indicate that intratumoral DPD expression is an efficient predictive factor not only in intravenous but also in oral 5-FU-based chemotherapy.

Although the range and median value of intratumoral TS gene expression were lower in the 7 patients with showing response to capecitabine (Table IV) the levels of difference did not reach statistical significance. However, because the trend in the survival curves between high and low TS expressors was in the expected direction, it is probably premature to exclude TS as a response determinant for capecitabine until a study is done with a larger number of responding patients. These results do suggest though that the relationship between TS expression and response to capecitabine may not be as strong as that for the parent drug 5-FU.
A.

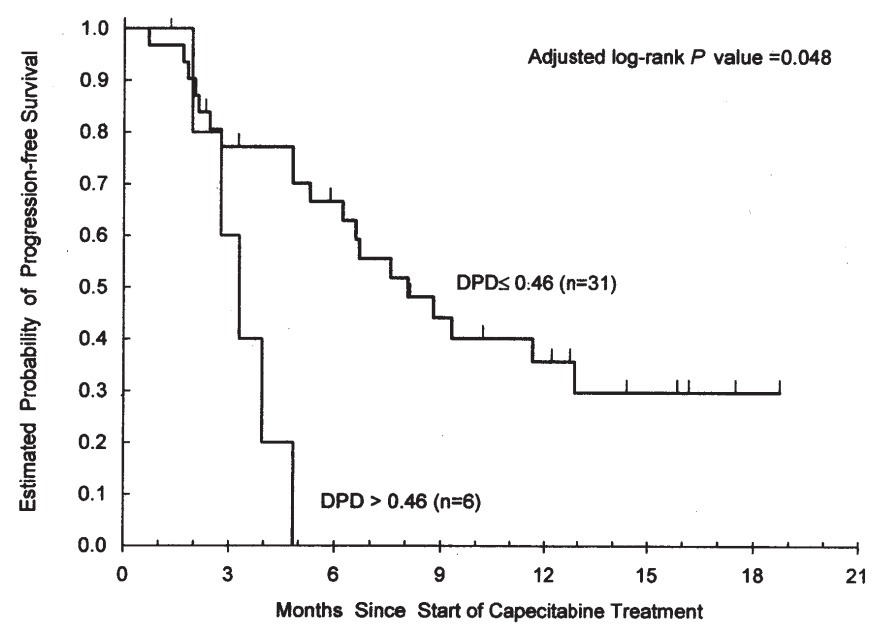

B.

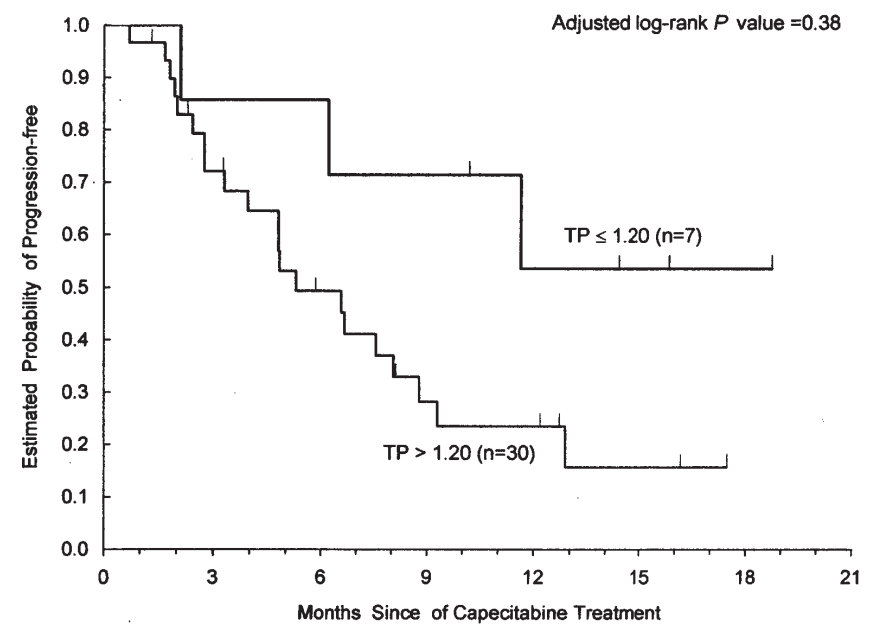

C.

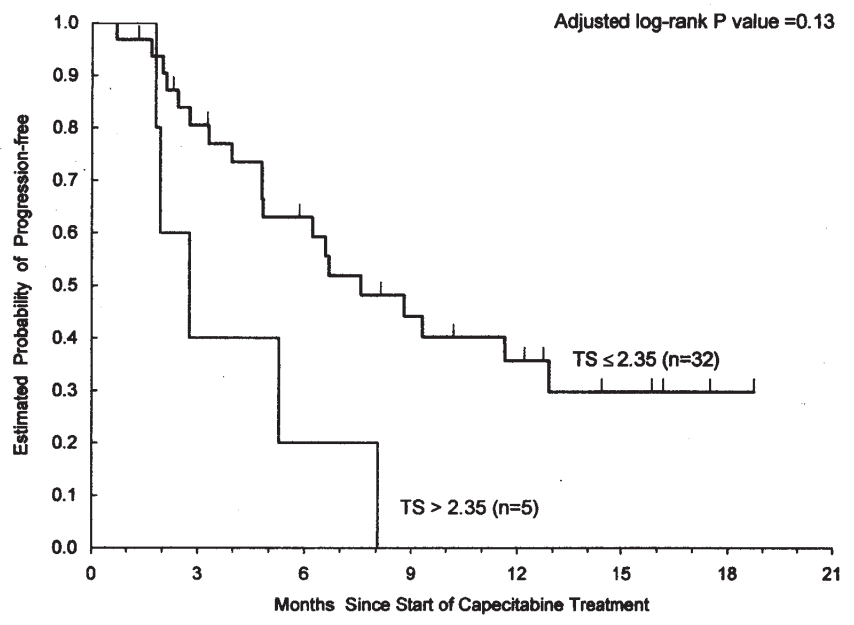

Figure 2. Plot of time to progression for the cohort of patients in relation to the dihydropyrimidine dehydrogenase, thymidine phosphorylase and thymidylate synthase mRNA expression level. DPD, dihydropyrimidine dehydrogenase; TP, thymidine phosphorylase; TS, thymidylate synthase.

TP putatively plays a crucial double role in the antitumor activity of capecitabine, first cleaving the molecule to generate free 5-FU, then in the reverse reaction, converting the resulting 5-FU to FdUMP (25). The prediction derived 
from this particular biological role of TP would be that high levels of TP should increase response to 5-FU-based therapy, a prediction that was supported by in vitro studies (15-17). In the present study, we did not find that high intratumoral TP expression was associated with better response to capecitabine treatment in the current set of patients; indeed, the trend we saw was in the opposite direction. However, this trend is consistent with two earlier studies regarding the relationship between TP expression and response to fluoropyrimidines. We previously had unexpectedly found that, contrary to the above model, the highest TP expressors in a group of metastatic CRC treated with 5-FU-based therapy actually had the worst response (13). To account for this unanticipated result, we hypothesized that the role of TP as an angiogenic agent (when it is known as platelet-derived endothelial cell growth factor) causes it to be an unfavorable prognostic factor that supersedes its function as as activating agent of 5-FU, while moreover, a high TP expression level does not necessarily guarantee a greater enzymatic activity of TP due to low levels of the co-substrate deoxyribose-1phosphate in tissues. In agreement, Jakob et al (26) also found that high TP expression predicted a poor response in rectal cancer treated with 5-FU-based radiochemotherapy, a result that these workers also hypothesized as probably due to the second role of TP as an angiogenic factor.

In conclusion, by using laser-capture microdissection and real-time RT-PCR, we were able to show in patients with metastatic $\mathrm{CRC}$ receiving first-line capecitabine that high intratumoral mRNA expression levels of DPD were significantly associated with resistance to chemotherapy, while those of TS or TP did not reach significant association. Furthermore, we could show that patients with a lower mRNA amount of DPD had a longer progression-free survival compared with patients that had a higher mRNA amount. These data indicate that DPD may be a useful predictive and prognostic factor in patients with metastatic $\mathrm{CRC}$ receiving capecitabine based chemotherapy. However, before concluding that TS expression is not a determinant of capecitabine activity on the basis of our data, a larger study should be done to confirm this result.

\section{References}

1. Heidelberger C, Chaudhuri NK, Danneberg P, et al: Fluorinated pyrimidines, a new class of tumour-inhibitory compounds. Nature 179: 663-666, 1957.

2. Meyerhardt JA and Mayer RJ: Systemic therapy for colorectal cancer. N Engl J Med 352: 476-487, 2005.

3. Meta-analysis Group In Cancer: Efficacy of intravenous continuous infusion of fluorouracil compared with bolus administration in advanced colorectal cancer. J Clin Oncol 16: 301-308, 1998

4. Walko CM and Lindley C: Capecitabine: a review. Clin Ther 27: 23-44, 2005.

5. Van Cutsem E, Twelves C, Cassidy J, et al: Oral capecitabine compared with intravenous fluorouracil plus leucovorin in patients with metastatic colorectal cancer: results of a large phase III study. J Clin Oncol 19: 4097-4106, 2001.

6. Hoff PM, Ansari R, Batist G, et al: Comparison of oral capecitabine versus intravenous fluorouracil plus leucovorin as first-line treatment in 605 patients with metastatic colorectal cancer: results of a randomized phase III study. J Clin Oncol 19: 2282-2292, 2001.

7. Leichman CG, Lenz HJ, Leichman L, et al: Quantitation of intratumoral thymidylate synthase expression predicts for disseminated colorectal cancer response and resistance to protracted-infusion fluorouracil and weekly leucovorin. J Clin Oncol 15: 3223-3229, 1997.

8. Beck A, Etienne MC, Cheradame S, Fischel JL, Formento P, Renee $\mathrm{N}$ and Milano G: A role for dihydropyrimidine dehydrogenase and thymidylate synthase in tumour sensitivity to fluorouracil. Eur J Cancer 30A: 1517-1522, 1994.

9. Ichikawa W, Uetake H, Shirota Y, et al: Combination of dihydropyrimidine dehydrogenase and thymidylate synthase gene expressions in primary tumors as predictive parameters for the efficacy of fluoropyrimidine-based chemotherapy for metastatic colorectal cancer. Clin Cancer Res 9: 786-791, 2003.

10. Johnston PG, Lenz HJ, Leichman CG, Danenberg KD, Allegra CJ, Danenberg PV and Leichman L: Thymidylate synthase gene and protein expression correlate and are associated with response to 5 -fluorouracil in human colorectal and gastric tumors. Cancer Res 55: 1407-1412, 1995.

11. Popat S, Matakidou A and Houlston RS: Thymidylate synthase expression and prognosis in colorectal cancer: a systematic review and meta-analysis. J Clin Oncol 22: 529-536, 2004.

12. Metzger R, Danenberg K, Leichman CG, et al: High basal level gene expression of thymidine phosphorylase (platelet-derived endothelial cell growth factor) in colorectal tumors is associated with non-response to 5-fluorouracil. Clin Cancer Res 4: 2371-2376, 1998.

13. Salonga D, Danenberg KD, Johnson M, et al: Colorectal tumors responding to 5-fluorouracil have low gene expression levels of dihydropyrimidine dehydrogenase, thymidylate synthase, and thymidine phosphorylase. Clin Cancer Res 6: 1322-1327, 2000.

14. Lindebjerg J, Nielsen JN, Hoeffding LD and Jakobsen A: Immunohistochemical expression of thymidylate synthase as predictor of response to capecitabine in patients with advanced colorectal adenocarcinoma. APMIS 113: 600-602, 2005.

15. Sawada N, Ishikawa T, Fukase $Y$, Nishida M, Yoshikubo T and Ishitsuka H: Induction of thymidine phosphorylase activity and enhancement of capecitabine efficacy by Taxol/Taxotere in human cancer xenografts. Clin Cancer Res 4: 1013-1019, 1998.

16. Sawada N, Ishikawa T, Sekiguchi F, Tanaka Y and Ishitsuka H: $\mathrm{X}$-ray irradiation induces thymidine phosphorylase and enhances the efficacy of capecitabine (Xeloda) in human cancer xenografts. Clin Cancer Res 5: 2948-2953, 1999.

17. Morita T, Matsuzaki A and Tokue A: Enhancement of sensitivity to capecitabine in human renal carcinoma cells transfected with thymidine phosphorylase cDNA. Int J Cancer 92: 451-456, 2001 .

18. Bonner RF, Emmert-Buck M, Cole K, Pohida T, Chuaqui R, Goldstein S and Liotta LA: Laser capture microdissection: molecular analysis of tissue. Science 278: 1481-1483, 1997.

19. Lord RV, Salonga D, Danenberg KD, et al: Telomerase reverse transcriptase expression is increased early in the Barrett's metaplasia, dysplasia, adenocarcinoma sequence. J Gastrointest Surg 4: 135-142, 2000.

20. Miller R and Siegmund D: Maximally selected Chi square statistics. Biometrics 38: 1011-1016, 1982.

21. Halpern J: Maximally selected Chi square statistics for small samples. Biometrics 38: 1017-1023, 1982.

22. Heggie GD, Sommadossi JP, Cross DS, Huster WJ and Diasio RB: Clinical pharmacokinetics of 5-fluorouracil and its metabolites in plasma, urine, and bile. Cancer Res 47: 2203-2206, 1987.

23. Isshi K, Sakuyama T, Gen T, Nakamura Y, Kuroda T, Katuyama T and Maekawa Y: Predicting 5-FU sensitivity using human colorectal cancer specimens: comparison of tumor dihydropyrimidine dehydrogenase and orotate phosphoribosyl transferase activities with in vitro chemosensitivity to 5-FU. Int J Clin Oncol 7: 335-342, 2002.

24. Tsuji T, Sawai T, Takeshita H, et al: Tumor dihydropyrimidine dehydrogenase in stage II and II colorectal cancer: low level expression is a beneficial marker in oral-adjuvant chemotherapy, but is also a predictor for poor prognosis in patients treated with curative surgery alone. Cancer Lett 204: 97-104, 2004.

25. Morita T, Matsuzaki A, Suzuki K and Tokue A: Role of thymidine phosphorylase in biomodulation of fluoropyrimidines. Curr Pharm Biotechnol 2: 257-267, 2001.

26. Jakob C, Liersch T, Meyer W, et al: Immunohistochemical analysis of thymidylate synthase, thymidine phosphorylase, and dihydropyrimidine dehydrogenase in rectal cancer (cUICC II/III): correlation with histopathologic tumor regression after 5-fluorouracil-based long-term neoadjuvant chemoradiotherapy. Am J Surg Pathol 29: 1304-1309, 2005. 